\title{
Burnout and Engagement at the Northernmost University in the World
}

\author{
Sabine Kaiser' $(\mathbb{D}$, Astrid M. Richardsen², \\ and Monica Martinussen'
}

\begin{abstract}
Few studies have looked at the relationship of job characteristics and worker well-being among Norwegian academics. The main purpose of this study was to examine the relationship between job demands, job resources, burnout, and engagement among Norwegian university staff. In total, 236 staff from one university in Norway answered the questionnaire. Hierarchical multiple regression analyses identified job demands as the most important predictors for burnout. Autonomy was the most important job resource in the prediction of engagement and burnout. What constitutes a job resource or a job demand varies from occupation to occupation. The present study adds to the existing literature by examining factors that may protect or harm the individual workers' health and well-being in a Norwegian university context.
\end{abstract}

\section{Keywords}

burnout, engagement, academic staff, university staff

\section{Introduction}

Academic work life today is characterized by increased demands in terms of workload, publication pressure, largescale organizational change, and cutbacks in government funding (Bentley et al., 2010; Gomes et al., 2013). Most universities record an increase in student numbers in addition to an increase in administrative duties among university employees (Naidoo-Chetty \& Plessis, 2021). Despite the fact that such increased demands may have serious consequences for faculty and staff in terms of psychological health and well-being, research on occupational stress and burnout among university teaching staff is relatively scarce (NaidooChetty \& Plessis, 2021; Watts \& Robertson, 2011). In a systematic literature review of burnout in university teaching staff, Watts and Robertson (2011) found only 12 published studies that met the criteria of being empirical studies and having sufficient methodological rigor to be included in an appraisal of the burnout literature in this population. The authors concluded that burnout is a considerable risk within full-time university teaching staff, but because of the limited number of studies and differing research techniques used, the individual and organizational predictors of stress and burnout in this population may not be representative.

The Job Demands-Resources (JD-R) model has been used extensively in burnout research over the years. The JD-R model, which was proposed by Demerouti et al. (2001), assumes that two processes are operating regarding work behavior. On one hand, high job demands require employees to increase effort and mobilize active coping responses that over time may deplete or exhaust their energy, resulting in burnout (Schaufeli \& Bakker, 2004). The second process is a motivational process in which job resources may reduce demands and facilitate achievement of work goals through the positive influence of work engagement (Bakker et al., 2010; Schaufeli \& Bakker, 2004). Furthermore, the JD-R model proposes that burnout leads to negative work outcomes (health problems, reduced productivity, intention to quit), whereas engagement leads to positive work outcomes (commitment, work performance) (Demerouti et al., 2001; Schaufeli \& Bakker, 2004).

A recently published review identified six articles published between 2014 and 2019 using the JD-R model among academic employees to identify job demands and resources inherent in the academic occupation (Naidoo-Chetty \& Plessis, 2021). Some of the identified job demands include workload, work pressure, job insecurity, conflict with colleagues, and work-family conflict. Some of the identified

'UiT The Arctic University of Norway, Tromsø, Norway

${ }^{2} \mathrm{BI}$ Norwegian Business School, Oslo, Norway

Corresponding Author:

Sabine Kaiser, RKBU North, UiT The Arctic University of Norway,

Tromsø, Troms, Norway.

Email: sabine.kaiser@uit.no 
job resources include autonomy, social support (from supervisors or colleagues), performance feedback, and self-development opportunities. Naidoo-Chetty and Plessis (2021) underline the importance of further research in the field.

In a longitudinal test of the model in a sample of Australian academics (Boyd et al., 2011), the results indicated robust longitudinal support for the motivational pathway proposed by the model. Time 1 resources predicted reduced job strain and increased organizational commitment. The health impairment pathway was only partially supported. The results also indicated the importance of two job resources, procedural fairness and autonomy, for the well-being of academics (Boyd et al., 2011). On the other hand, two crosssectional studies conducted among university teachers in China (Han et al., 2020) and among faculty members in universities in the Czech Republic (Mudrak et al., 2018) found support for the health impairment and motivational processes as proposed by the JD-R model. A meta-analytic review that validated the assumptions of the JD-R model concludes that it " . . . is an excellent theoretical basis to describe employee well-being in a broad range of organisations and occupational fields" (Lesener et al., 2019, p. 96).

Occupational stress over time may lead to negative consequences for individuals in terms of work quality, productivity, and health and well-being (Cooper et al., 2001). Burnout is characterized by feelings of emotional exhaustion (e.g., feeling emotionally drained and exhausted), cynicism (e.g., becoming cynical and negative), and reduced professional efficacy (e.g., feelings of reduced professional competence), and is a response to chronic job stress (Maslach, 1998). It is also well known that prolonged occupational stress has negative consequences for organizations in terms of lost productivity and turnover. Much less is known about the specific impact of stress in the university sector (Gillespie et al., 2001). In a study of the causes and consequences of occupational stress in Australian universities (Gillespie et al., 2001), the researchers found that the most common sources of stress reported by faculty and staff from 15 Australian universities were lack of funding, resources, and support; task overload; poor leadership and management; job insecurity; and lack of promotion, reward, and recognition. These sources of stress had consequences both at the professional level (poor job performance, poor work relationships, low commitment, and withdrawal from role) and at the personal level (physical and psychological health problems, strained personal relationships, and poor quality of life). These consequences were moderated by both job resources (social support, recognition and achievement, flexible work) and personal resources (stress management techniques, work-home balance, tight role boundaries).

A study tested the Demand-Control-Support model in 166 academics at a U.K. university (McClenahan et al., 2007). The results indicated additive effects of job demands and control on psychological well-being, and of job demands and support on both burnout and job satisfaction. No support was found for the hypothesized three-way interaction between demands, control, and support (McClenahan et al., 2007).

Barkhuizen et al. (2014) found that burnout was positively related to physical symptoms of stress as well as stress-induced mental health problems. A study of educator's burnout in South Africa (Pretorius, 1994) found that role conflict, role ambiguity, and number of students were positively related to emotional exhaustion and depersonalization, whereas participation in decision making was positively related to personal accomplishment.

A sample of multi-occupational staff at a Spanish university was studied to assess risk of certain burnout types (Montero-Marin et al., 2011). This cross-sectional study found that employees working more than $40 \mathrm{hr}$ per week as opposed to those working fewer than $35 \mathrm{hr}$ per week were more at risk for "frenetic" burnout. Administrative and service personnel had a greater risk of "underchallenged" burnout than academic staff, and those working more than 16 years had greater risk for "worn-out" burnout compared with those with less than $4 \mathrm{hr}$ of service (Montero-Marin et al., 2011).

A study conducted by Converso et al. (2019) examined the relation of two job demands, that is, work overload and conflict among colleagues, with burnout, and workaholism, and found that the associations were in the expected directions. A report on working conditions for Norwegian academics (Bentley et al., 2010) indicated that a number of these stressors also may exist at Norwegian universities. A significant percentage ( $20 \%$ or more) of faculty reported dissatisfaction with teaching facilities, technological support for teaching, equipment and instruments for research, and administrative support for teaching and research. While most academics were satisfied with their job and career, almost $40 \%$ indicated that the job also represented a considerable amount of personal strain. Communication and management support were also sources of dissatisfaction, and almost $40 \%$ indicated lack of competent leadership by top management. Another report on working hours among faculty working in Norwegian universities and university colleges indicated long working hours $(46.7 \mathrm{hr} /$ week) and dissatisfaction with the time allocated to do research (Egeland \& Bergene, 2012). These reports suggest some existing job demands among Norwegian academics, but there are no studies that have looked at the relationship of such demands to individual health and well-being and important organizational outcomes in Norway.

While it is important to understand the factors in the workplace that may lead to occupational stress, it is also important to understand what could turn this around and lead to people feeling engaged, motivated, and performing optimally (Bakker, 2017; Richardsen, 2019). The trend toward positive psychology represents a shift in focus toward human strength and optimal functioning rather than on weaknesses and poor functioning (Fairlie, 2017; Linley et al., 2006). It 
will be beneficial for our understanding of individuals and organizations to look at the role of a more positive state of mind, that is, engagement with work (Demerouti et al., 2001). Engagement with work has been defined as the opposite of stress and burnout (Maslach, 1998; Maslach \& Leiter, 1997), or a positive, fulfilling, work-related state of mind that is characterized by vigor, dedication, and absorption (Schaufeli \& Bakker, 2004; Schaufeli et al., 2002). It represents a motivational process in which available job resources will stimulate activity and work performance (Bakker et al., 2003). The fact that many Norwegian academics report high job and career satisfaction (Bentley et al., 2010) indicates that there are aspects of the academic work situation that contribute to work engagement and motivation to perform.

International studies of academic staff have found that job resources are positively related to work engagement. In a study of 422 academicians from universities all around Turkey, it was found that resources such as autonomy, social support from colleagues, coaching by senior staff, task significance, and opportunities for personal development were all strong predictors of job engagement (Altunel et al., 2015). The study by Converso et al. (2019) found that meaningfulness and reward were positively related to engagement. Eldor and Shoshani (2016) studied 226 Israeli teachers and found that expressions of compassion from colleagues and principals related positively to teachers' emotional vigor, organizational commitment, and job satisfaction, and also helped teachers cope with stressful teaching conditions. Job demands (workload) and resources (supervisor support, role clarity, and task characteristics) predicted burnout and engagement among 595 academics from six South African universities, as hypothesized by the JD-R model (Barkhuizen et al., 2014). Their results also showed a strong indirect effect of dispositional optimism on burnout, engagement, ill health, and organizational commitment. Dispositional optimism was negatively related to burnout and had a strong positive relationship with job resources, indicating that personal resources in the form of a generalized expectation of positive outcomes in various life domains affected the ability to control and influence one's work environment (Barkhuizen et al., 2014).

Some studies have looked at the relationship between job engagement and various work outcomes. For example, Lauring and Selmer (2015) found that the various aspects of job engagement were differentially related to work outcomes in a sample of expatriate academics in Singapore. Physical engagement or vigor was positively associated with adjustment to the job and actual work performance, emotional engagement or dedication was associated with shorter time to proficiency in the job and high job satisfaction, while cognitive engagement or the ability to be absorbed in one's work was associated with reduced satisfaction and well-being (Lauring \& Selmer, 2015). Barkhuizen et al. (2014) found that engagement was positively associated with organizational commitment. Similarly, a study of lecturers at a university in Indonesia found that engagement was related to job satisfaction, which in turn was associated with organizational citizenship behavior (Affandi et al., 2019). Another study of lecturers from Indonesia found that job resources moderated the relationship between job demands and engagement (Nurendra, 2018). A study conducted in Jordanian universities found that the relationship between job demands and resources on engagement was mediated by job satisfaction (Alzyoud, 2016).

To sum up, some research examining burnout and engagement in different universities all over the world has been conducted, but there is still a need to develop knowledge that provides the basis for evidence-based practice for promoting health and productivity in academic work life in Norway or Scandinavia. That is because the Nordic countries stand out in terms of strong trade unions and good welfare regulations such as parental leave, 5 weeks paid vacation, and sick leave pay. An important aspect is to discover factors that may protect the individual against excessive work demands and burnout and that foster engagement. The aim of the current study was to identify job demands (workload, work conflicts, and work-family conflicts) and job resources (autonomy, leader support, leader trust, and procedural justice) that were related to burnout and engagement in a sample of Norwegian university staff. In accordance with previously published studies, job demands were expected to be positively related to burnout and negatively related to engagement, while job resources were expected to be negatively related to burnout and positively related to engagement (Han et al., 2020; Kaiser et al., 2020; Martinussen et al., 2017; Mudrak et al., 2018).

Leadership has traditionally not been included in the JD-R model; however, more recent studies have indicated that positive or constructive leadership may be seen as a job resource (Kaiser et al., 2020), and also that the effect may be indirect by moderating the effects of demands and resources on burnout (Schaufeli, 2015). We therefore wanted to examine the potential moderating effect of leadership on the relationship between job demands and burnout and engagement. We hypothesized that leadership would have a buffering impact on the negative effects that job demands can have on burnout and engagement.

Another aim was to compare the level of engagement and burnout in the current sample with the level of engagement and burnout among other samples such as different occupational groups in Norway. It was expected that the mean level of burnout and engagement would be comparable with the mean level of burnout and engagement in other occupational groups in Norway. However, we also expect that the mean level of burnout and engagement among Norwegian academic staff would be more favorable than compared with foreign academic staff, possibly because of better working conditions such as paid maternity leave or sick leave and strong trade unions in Norway. 


\section{Method}

\section{Participants and Procedure}

The questionnaires and the information letters were distributed to members of the Norwegian Association of Researchers (NAR) at one of the larger universities in Norway by local union representatives in 2013. The NAR is the largest trade union at the university, organizing staff with higher education from all disciplines. It included both academic, technical, and administrative staff working at the university. The completed forms were returned in stamped and addressed envelopes to the Norwegian Business School. The study was approved by the Norwegian Data Inspectorate. The total number of union members was approximately 700 when the survey was distributed, and the number of participants who answered the questionnaire was 238 , which results in a response rate of $34 \%$. The mean age of the participants was $48.23(S D=10.00, n=235)$ and about $61 \%(n=143)$ of the sample were women. The mean number of working hours per week was $44.07(S D=8.85, n=231)$; 80\% $(n=189)$ of the sample had a scientific position and $31 \%(n=74)$ of the sample had leader responsibility.

\section{Measures}

Demographic variables and aspects of the workplace. The survey included demographic variables (e.g., age, gender) and questions about type of position, leadership responsibilities (yes/no), and working hours per week.

Job demands. Workload was assessed with a scale derived from the Total Workload Questionnaire (TWQ; Østlyngen et al., 2003). The scale includes five items (e.g., "How stressful is your job?" or "Do you feel that you have too much to do?"), measured from 1 (not at all) to 7 (to a very large extent). The degree of work conflict and work-family conflict was measured with four questions from McKeen and Burke (1991; for example, "I often experience conflicts with other colleagues at work" or "I often feel a conflict between my work and my family roles or other obligations"). Cronbach`s alpha was adequate for workload $(\alpha=.71)$ and work conflict ( $\alpha=.72$ ), and good for work-family conflict ( $\alpha=.85$ ). These three job demands have been used in previously conducted research and found to be important predictors for worker well-being in different samples of health care professionals (Kaiser et al., 2020; Martinussen et al., 2017).

Job resources. Autonomy in the workplace was also measured by a scale obtained from the TWQ (Østlyngen et al., 2003) and has been used in previous research in different samples of health care professionals (Kaiser et al., 2020; Martinussen et al., 2017). The scale includes five items (e.g., "To what extent do you have direct influence on what you do in your job?" or "To what extent can you, on your own initiative, realize your own ideas in your job?"), measured from 1 (not at all) to 7 (to a very large extent). Cronbach's alpha was good for autonomy ( $\alpha=.88$ ). Two scales were used to assess different aspects of leadership, including Leader Support which included six items (Kuvaas \& Dysvik, 2010), and Leader Trust with eight items from Winefield et al. (2003). The questions included in the Leader Support scale (e.g., "My superior really cares about my opinions" or "takes an interest in my well-being at work") were answered on a 5-point scale (1 = completely agree to $5=$ completely disagree). The questions included in the Leader Trust scale (e.g., "My department head/leader can be trusted") were answered on a 5-point scale $(1=$ completely agree to $5=$ completely disagree $)$. Cronbach's alpha was excellent for both Leader Support and Leader Trust ( $\alpha=.93$ and $\alpha=.96)$. Aspects of organizational justice were measured with the scale Procedural Justice. The questions were used in a previous study of Australian researchers (Winefield et al., 2003) and included a total of five questions (e.g., "at my university, the procedures for advancement are fair") answered on a 5-point scale from 1 (completely disagree) to 5 (completely agree). The estimated Cronbach's alpha was good $(\alpha=.82)$.

Employee well-being. To measure engagement, the short version of the Utrecht Work Engagement Scale (UWES-9) was used (Nerstad et al., 2010; Schaufeli et al., 2006). The psychometric properties of the Norwegian version of the scale have been found to be good among different Norwegian samples (Nerstad et al., 2010). It consists of three scales: Vitality, Enthusiasm, and Ability for Introspection. In this study, the total score was used, as measured by nine items (e.g., "I am full of energy in my work," "I am proud of the work I do," or "I feel happy when I am immersed in my work"). The questions were rated on a scale from 0 (never) to 6 (every day). Cronbach's alpha for the scale was excellent $(\alpha=.91)$. The subscale Exhaustion from the Norwegian version of the Maslach Burnout Inventory-General Survey (MBI-GS) was used as it represents the core dimension of burnout (Maslach et al., 1996; Richardsen \& Martinussen, 2005). The psychometric properties of the Norwegian version of the inventory have been found to be good among different Norwegian samples (Richardsen \& Martinussen, 2005). The scale ranges from 0 (never) to 6 (every day). The scale consists of five items (e.g., "I feel emotionally drained by my work" or "I feel exhausted by the end of the workday"). Internal consistency was excellent ( $\alpha=.87)$.

\section{Data Analysis}

The statistical analyses were performed with the Statistical Package for the Social Sciences (SPSS, Version 26). Cronbach's alpha was calculated for the different scales. Values above .70 are considered as adequate, values of .80 or above as good, and values of .90 or higher as excellent (European Federation of Psychologists' Association, 2013). Because the two scales Leader Support and Leader Trust 


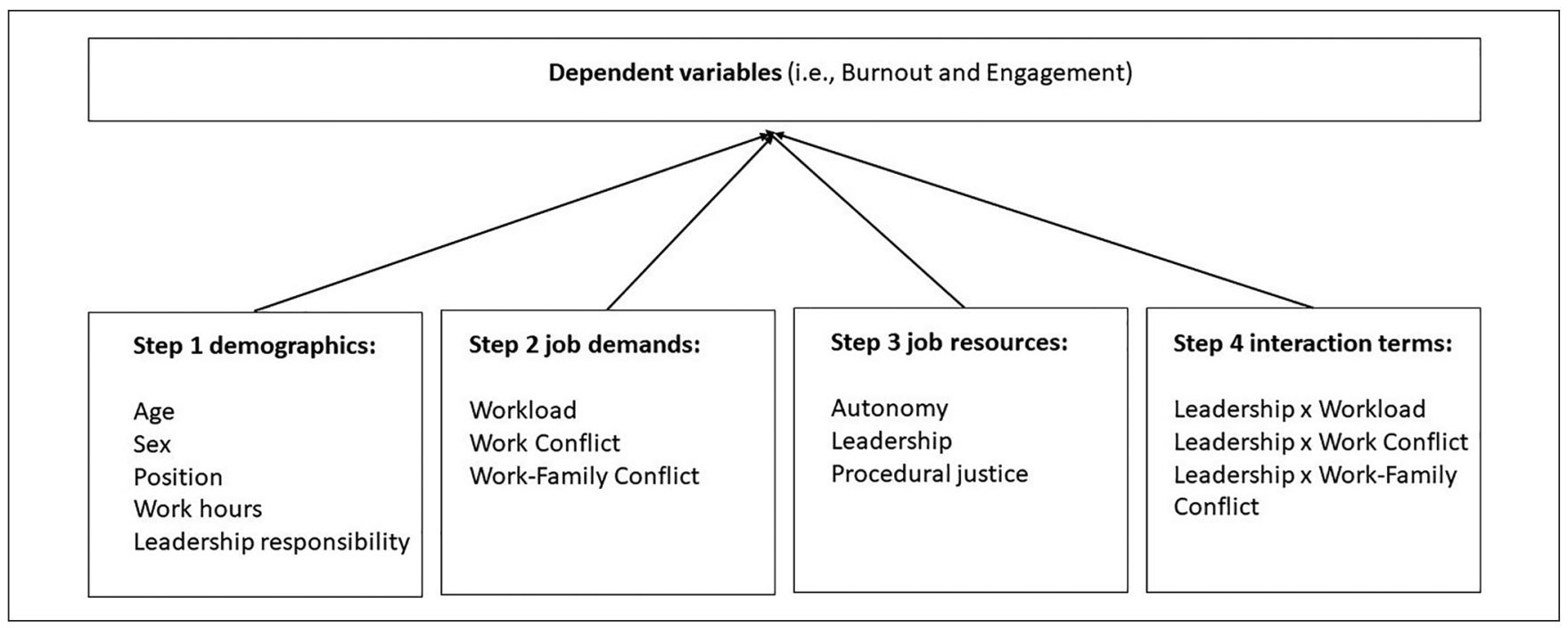

Figure I. Theoretical model of the hierarchical multiple regression analyses to predict burnout and engagement.

were highly correlated $(r=.83, p<.01)$, they were combined into one scale called Leadership ( $\alpha=.97 ; 14$ items). Two hierarchical multiple regression analyses were conducted to predict Burnout, measured by its core dimension exhaustion, and Engagement (see Figure 1). We controlled for demographic characteristics - age in years, sex (women or men), type of position (technical/administrative or scientific), work hours per week, and leadership responsibility (yes or no)-in Step 1, and continued by entering job demands in Step 2-workload, work conflict, and workfamily conflict-and job resources in Step 3-autonomy, leadership, and procedural justice. Furthermore, Step 4 included interaction terms between Workload, Work Conflict and Work-Family Conflict, and Leadership, respectively, to examine the potential moderating effect of leadership on the relationship between job demands and burnout and engagement. For this purpose, all independent, continuous predictors were centered as suggested by Aiken and West (1991). In addition to those analyses, $t$ tests were conducted to compare burnout and engagement of the current sample with other samples. Effect sizes of Hedges's $g=0.20$ indicate small effect sizes, while Hedges's $g$ of 0.50 and 0.80 indicate medium and large effect sizes (Cohen, 1988).

\section{Results}

\section{Descriptive Statistics and Correlations}

Table 1 presents the means and standard deviations, and the correlations between the variables. All correlations were in the expected directions. The strongest correlations were found between workload and burnout $(r=.44, p<.01)$, and workfamily conflict and burnout $(r=.44, p<.01)$. Leadership was negatively correlated with burnout $(r=-.19, p<.01)$ and positively correlated with engagement $(r=.19, p<.01)$.

\section{Predicting Burnout and Engagement}

Table 2 presents the results of the hierarchical multiple regression analyses for the prediction of burnout and engagement. The model explained 39\% the variance in burnout and 33\% in engagement. Demographic characteristics (Step 1) explained a significant amount of variance in engagement (11\%) but not in burnout (1\%). Job demands on Step 2 (workload, work conflict, and work-family conflict) added most of the explained variance to burnout (32\%) and $8 \%$ to engagement. Job resources on Step 3 explained most of the variance in engagement (13\%) and only $6 \%$ in burnout. The only significant job resource for engagement was autonomy, which was also significantly and negatively related to burnout. The interaction terms between the three different job demands and leadership were not significant for any of the outcomes.

\section{Burnout and Engagement in Different Groups}

Burnout in terms of exhaustion was significantly lower in the current sample $(M=1.86, S D=1.32, n=238)$ compared with exhaustion in a sample of academics in the United Kingdom $(M=2.73, S D=1.67, n=166 ; t=5.83, p<$ .001 , Hedges's $g=0.59$; McClenahan et al., 2007) or exhaustion among a sample of four different Norwegian occupational groups $(M=2.17, S D=1.32, n=1,590 ; t=$ $3.37, p<.001$, Hedges's $g=0.23$; Richardsen \& Martinussen, 2005). There was no significant difference in exhaustion between the current sample and a sample of Norwegian health care workers $(M=1.71, S D=1.25, n=485 ; t=$ $-1.49, p>.05$, Hedges's $g=0.12$; Kaiser et al., 2020).

Engagement was significantly higher in the current sample $(M=4.36, S D=1.07, n=238)$ compared with engagement across different occupational groups in Norway $(M=$ 3.92, $S D=1.20, n=1,266 ; t=-5.27, p<.001$; Nerstad 
Table I. Descriptive Statistics and Correlations for Variables in the Study $(n=236-238)$.

\begin{tabular}{|c|c|c|c|c|c|c|c|c|c|c|c|c|c|c|}
\hline Variables & M & $S D$ & I. & 2. & 3. & 4. & 5. & 6. & 7. & 8. & 9. & 10. & II. & 12. \\
\hline \multicolumn{15}{|l|}{ Demographics } \\
\hline I. Age in years & 48.23 & 10.00 & - & & & & & & & & & & & \\
\hline $\begin{array}{l}\text { 2. } \operatorname{Sex}(0=\text { women, } \\
\mathrm{I}=\text { men })\end{array}$ & - & - & $.15^{*}$ & - & & & & & & & & & & \\
\hline $\begin{array}{l}\text { 3. Position }(0= \\
\text { administrative, } \mathrm{I}= \\
\text { scientific) }\end{array}$ & - & - & $.14 *$ & .04 & - & & & & & & & & & \\
\hline $\begin{array}{l}\text { 4. Leader responsibility } \\
(0=\text { yes, } I=\text { no })\end{array}$ & - & - & $-.16 *$ & .02 & .07 & - & & & & & & & & \\
\hline 5. Work hours per week & 44.07 & 8.85 & .07 & .05 & $.24 * *$ & $-.23 * *$ & - & & & & & & & \\
\hline \multicolumn{15}{|c|}{ Job demands } \\
\hline 6. Workload & 4.15 & 1.05 & .05 & -.00 & .07 & $-.13^{*}$ & $.24 * *$ & - & & & & & & \\
\hline 7. Work conflict & 2.01 & 1.17 & .09 & .07 & $.19 * *$ & -.03 & $.14 *$ & $.24 * *$ & - & & & & & \\
\hline 8. Work-family conflict & 3.32 & 1.75 & $-.28 * *$ & -.05 & .01 & -.12 & $.26 * *$ & $.43 * *$ & $.20 * *$ & - & & & & \\
\hline \multicolumn{15}{|l|}{ Job resources } \\
\hline 9. Autonomy & 5.07 & 1.06 & -.11 & .01 & .09 & -.12 & -.00 & $-.32 * *$ & $-.17 * *$ & -.12 & - & & & \\
\hline I0. Leadership & 3.49 & 1.05 & $-.17 * *$ & -.04 & $-.24 * *$ & -.06 & -.04 & -.11 & $-.43 * *$ & -.03 & $.31 * *$ & - & & \\
\hline II. Procedural justice & 2.75 & 0.76 & .05 & -.06 & -.01 & $-.19 * *$ & -.01 & -.06 & $-.15^{*}$ & .00 & $.29 * *$ & $.33^{* *}$ & - & \\
\hline \multicolumn{15}{|l|}{ Worker well-being } \\
\hline 12. Burnout & 1.86 & 1.32 & -.08 & -.04 & .05 & -.03 & .05 & $.44 * *$ & $.29 *$ & $.44 * *$ & $-.34 * *$ & $-.19 * *$ & $-.15^{*}$ & - \\
\hline I3. Engagement & 4.36 & 1.07 & .06 & $-.14^{*}$ & $.19 * *$ & $-.16 *$ & $.17 *$ & $-.16^{*}$ & -.12 & $-.15^{*}$ & $.43 * *$ & $.19 * *$ & $.23 * *$ & $-.39 * *$ \\
\hline
\end{tabular}

$*_{p}<.05 . * *_{p}<.01$ (two-tailed).

Table 2. Hierarchical Multiple Regression Analysis Results for the Prediction of Burnout and Engagement $(n=228)$.

\begin{tabular}{|c|c|c|c|c|}
\hline \multirow[b]{2}{*}{ Predictor } & \multicolumn{2}{|c|}{ Burnout } & \multicolumn{2}{|c|}{ Engagement } \\
\hline & $\Delta R^{2}$ & $B$ & $\Delta R^{2}$ & $B$ \\
\hline Step I: Demographics & .01 & & $.11 * * *$ & \\
\hline Age in years & & -.00 & & -.00 \\
\hline $\operatorname{Sex}(0=$ women, $I=$ men $)$ & & -.01 & & $-.35 * *$ \\
\hline Position ( $0=$ administrative, $\mathrm{I}=$ scientific $)$ & & .06 & & $.54 * *$ \\
\hline Leader responsibility $(0=$ yes, $\mathrm{I}=\mathrm{no})$ & & -.02 & & -.22 \\
\hline Work hours per week & & $-.02 * *$ & & $.02 * *$ \\
\hline Step 2: Job demands & $.32 * * *$ & & $.08 * * *$ & \\
\hline Workload & & $.31 * * *$ & & -.07 \\
\hline Work conflict & & $.21 * *$ & & -.08 \\
\hline Work-family conflict & & $.21 * * *$ & & -.07 \\
\hline Step 3: Job resources & $.06 * * *$ & & $.13 * * *$ & \\
\hline Autonomy & & $-.28 * * *$ & & $.29 * * *$ \\
\hline Leadership & & -.03 & & .07 \\
\hline Procedural justice & & -.07 & & .16 \\
\hline Step 4: Interaction & .01 & & .01 & \\
\hline Workload $\times$ Leadership & & .09 & & .04 \\
\hline Work Conflict $\times$ Leadership & & .08 & & -.09 \\
\hline Work-Family Conflict $\times$ Leadership & & -.00 & & .01 \\
\hline Total $R^{2}$ & $.39 * * *$ & & $.33 * * *$ & \\
\hline
\end{tabular}

Note. The unstandardized $B$ coefficients were from the final model with all four steps included.

$* * p<.01$. ***p $<.001$. 
et al., 2010). The effect size was small (Hedges's $g=0.37$ ). There was no difference in engagement between the current sample and a sample of Norwegian health care workers $(M$ $=4.42, S D=1.01, n=485 ; t=0.74, p>.05$, Hedges's $g$ $=0.06$; Kaiser et al., 2020).

\section{Discussion}

The present study investigated the relationship between various work demands typical in academic settings and common resources for psychological health and well-being in a Norwegian university. All job demands (workload, work conflict, and work-family conflict) were related to burnout indicating the need to keep these occupational stressors low. This finding is in line with results from previous research (Aronsson et al., 2017). Studies over the past 30 years have shown that workload (Alarcon, 2011; Richardsen et al., 1992), work conflicts, and work-family conflicts (Kaiser et al., 2020; Martinussen et al., 2007, 2017; Martinussen \& Richardsen, 2006; Richardsen et al., 2006) are contributing to the exhaustion that characterizes burnout.

At the same time, important work resources such as social support, autonomy, opportunities to learn and develop, and performance feedback have frequently been associated with engagement (Bakker et al., 2003; Schaufeli \& Bakker, 2004). In the current study, autonomy was negatively related to burnout indicating a protective functioning for the development of exhaustion. Autonomy was the only significant predictor for engagement in the regression model considering job demands and resources, underlining the twofold importance of giving the university staff freedom to organize their work. Procedural justice was not significantly related to burnout or engagement in the regression model. These findings are not in line with results from Boyd et al. (2011) in a longitudinal study of Australian academics, who identified the importance of the two job resources, procedural fairness and autonomy, for the well-being of academics. In addition, the job resource of leadership, that consisted of leader support and leader trust, was not a significant predictor for any of the outcomes nor did it moderate the effect of job demands on burnout or engagement. This is surprising as poor leadership and management were found to be a source of stress by faculty and staff from different Australian universities (Gillespie et al., 2001). Similarly, a report on working conditions for Norwegian academics (Bentley et al., 2010) indicated a lack of competent leadership as a source of dissatisfaction. Schaufeli (2015) found that leadership had only an indirect effect on employee burnout and engagement, and developing leadership behavior was found to be a moderator between human resource practices and worker well-being in a study of seven larger organizations in Belgium (Marescaux et al., 2019). However, in our study, leader support and trust were negatively related to work conflict and positively related to autonomy and procedural justice. Thus, it may be that good leadership in an academic setting involves directly reducing work conflicts and supporting autonomy of academic staff, while making sure that organizational procedures are fair and just.

The findings of the present study indicate that the level of exhaustion was lower in the present sample compared with the level of exhaustion in another university sample from the United Kingdom or among other Norwegian occupational groups, except for Norwegian health care workers. At the same time, the level of engagement was relatively high in the current sample especially compared with a sample among different Norwegian occupational groups, except for the level of engagement in Norwegian health care workers. Taking into account the assumptions of the JD-R model, these findings might indicate a good balance between job demands and job resources among Norwegian university staff. However, universities and colleges all over the world, Norway included, are undergoing large-scale organizational change. These changes include restructuring, mergers between institutions, and government funding increasingly based on performance (e.g., publishing, graduating students). While traditionally thought of as a low-stress occupation because of tenure, flexibility, autonomy in terms of pursuing research interests, and "perks" such as sabbaticals and conference travels, there are now a number of research reports that show increases in stress among academic and general staff at universities around the world (Gillespie et al., 2001; Gomes et al., 2013). Many of the advantages of working in academia may have eroded, there are increased workloads, salaries are lower compared with the commercial sector, and there is increased pressure to obtain external research funding and to publish. In a multinational survey of university faculty in Norway, Finland, Germany, Great Britain, the United States, Canada, and Australia (Bentley et al., 2010), the results indicated that a higher percentage of Norwegian university employees reported that working conditions had become worse over the past years, than university employees in the other countries. These findings indicate a need for identifying relevant job demands and job resources in the university setting to adapt the workplace accordingly and to further promote healthy workplaces in Norwegian universities in the future.

\section{Limitations}

Limitations of the study were that cross-sectional data were used in the analyses and that it is not possible to make causal conclusions (Kesmodel, 2018). The use of self-report questionnaires in research is an effective way for collecting a large amount of data. However, self-report questionnaires may be prone to common method bias as the independent and dependent variables are based on the same measures filled in by the same sample who might, in addition, have answered questions in a socially desirable way (Jordan \& 
Troth, 2020). Another limitation is the low response rate of about $34 \%$ in the current study. However, even lower response rates $(23 \%)$ among academic staff have been reported by McClenahan et al. (2007).

\section{Conclusion}

The present study examined the relationship between factors of the work environment and employee health. What constitutes a job resource or a job demand might vary from occupation to occupation. It is, therefore, important to discover factors that may protect or harm the individual workers' health and well-being. The current study is one of very few to investigate the relationship of such factors among Norwegian academics. The sector is characterized by high workload, high achievement pressure, and frequent organizational changes. The findings of the current study provide the basis for evidence-based practice for promoting health in academic work life. While it is common for academics to work long hours, the results suggest that to reduce the risk of burnout, academic leaders and HR (human resources) departments would do well to monitor workloads for their academic staff. Similarly, reducing work conflict and work-family interference will help academic staff to balance demands both on and off the job. Academic leaders would also do well to support the autonomy that academics so highly value in their jobs. Being able to decide how to structure and prioritize their own work seems to alleviate the emotional exhaustion of burnout and at the same time increase the excitement, dedication, and commitment that characterize work engagement. The study shows that burnout in this occupational group is less of a problem than in many other occupations, and that engagement is high. It is unclear how the increased demands of academic work, such as large-scale organizational change, increased administrative work, and pressure to obtain research funding and to publish, will affect academic staff over time. More longitudinal research is needed to examine how changes in the workplace may affect worker health and engagement. The challenge for leaders will be to identify and support desired job resources among employees working at universities to maintain a high level of engagement with work. A combination of quantitative and qualitative methods could provide more clarity on these issues.

\section{Declaration of Conflicting Interest}

The author(s) declared the following potential conflicts of interest with respect to the research, authorship, and/or publication of this article: The authors have no competing interests to declare. Monica Martinussen has been actively involved in the Norwegian Association of Researchers for many years both at the local level and at the national level.

\section{Funding}

The author(s) disclosed receipt of the following financial support for the research, authorship, and/or publication of this article: The study is funded by BI Norwegian Business School and UiT The Arctic University of Norway.

\section{ORCID iD}

Sabine Kaiser (iD https://orcid.org/0000-0002-2081-7734

\section{Data Availability}

The data used in this research project have not been made available because participants did not agree for their data to be shared publicly.

\section{References}

Affandi, A., Patrisia, D., \& Syahrizal Abror, A. (2019). The effect of employee engagement and job satisfaction on Organizational Citizenship Behavior (OCB). https://doi.org/10.2991/piceeba218.2019.69

Aiken, L. S., \& West, S. G. (1991). Multiple regression: Testing and interpreting interactions. SAGE.

Alarcon, G. M. (2011). A meta-analysis of burnout with job demands, resources, and attitudes. Journal of Vocational Behavior, 79(2), 549-562. https://doi.org/10.1016/j.jvb.2011.03.007

Altunel, M. C., Kocak, O. E., \& Cankir, B. (2015). The effect of job resources on work engagement: A study on academicians in Turkey. Educational Sciences-Theory \& Practice, 15(2), 409-417. https://doi.org/10.12738/estp.2015.2.2349

Alzyoud, A. A. Y. (2016). Job demands and job resources on work engagement mediating by job satisfaction in Jordan higher education sector. International Journal of Social Science \& Economic Research, 1(5), 488-506.

Aronsson, G., Theorell, T., Grape, T., Hammarström, A., Hogstedt, C., Marteinsdottir, I., Skoog, I., Träskman-Bendz, L., \& Hall, C. (2017). A systematic review including meta-analysis of work environment and burnout symptoms. BMC Public Health, 17(1), Article 264. https://doi.org/10.1186/s12889-017-4153-7

Bakker, A. B. (2017). Strategic and proactive approaches to work engagement. Organizational Dynamics, 46(2), 67-75. https:// doi.org/10.1016/j.orgdyn.2017.04.002

Bakker, A. B., Boyd, C. M., Dollard, M., Gillespie, N., Winefield, A. H., \& Stough, C. (2010). The role of personality in the Job Demands-Resources model: A study of Australian academic staff. Career Development International, 15, 622-636. https:// doi.org/10.1108/13620431011094050

Bakker, A. B., Demerouti, E., Taris, T. W., Schaufeli, W. B., \& Schreurs, P. J. G. (2003). A multigroup analysis of the job demands-resources model in four home care organizations. International Journal of Stress Management, 10(1), 16-38. https://doi.org/10.1037/1072-5245.10.1.16

Barkhuizen, N., Rothmann, S., \& van de Vijver, F. J. R. (2014). Burnout and work engagement of academics in higher education institutions: Effects of dispositional optimism. Stress and Health, 30(4), 322-332. https://doi.org/10.1002/smi.2520

Bentley, P., Kyvik, S., Vabø, A., \& Waagene, E. (2010). Forskningsvilkår ved norske universitetet $i$ et internasjonalt perspektiv [Research conditions at the Norwegian University in an international perspective] (NIFU STEP: Rapport 8/2010.). https://www.nifu.no/publications/934100/

Boyd, C. M., Bakker, A. B., Pignata, S., Winefield, A. H., Gillespie, N., \& Stough, C. (2011). A longitudinal test of the 
job demands-resources model among Australian university academics. Applied Psychology-An International ReviewPsychologie Appliquee-Revue Internationale, 60(1), 112-140. https://doi.org/10.1111/j.1464-0597.2010.00429.x

Cohen, J. (1988). Statistical power analysis for the behavioral sciences (2nd ed.). Lawrence Erlbaum.

Converso, D., Sottimano, I., Molinengo, G., \& Loera, B. (2019). The unbearable lightness of the academic work: The positive and negative sides of heavy work investment in a sample of Italian university professors and researchers. Sustainability, 11(8), Article 2439. https://www.mdpi.com/2071-1050/11/8/2439

Cooper, C., Dewe, P., \& O’Driscoll, M. P. (2001). Organizational stress: A review and critique of theory, research, and applications. SAGE.

Demerouti, E., Bakker, A. B., Nachreiner, F., \& Schaufeli, W. B. (2001). The Job Demands-Resources model of burnout. Journal of Applied Psychology, 86, 499-512. https://doi.org /10.1037/0021-9010.86.3.499

Egeland, C., \& Bergene, A. C. (2012). Tidsbruk, arbeidstid, og tidskonflikter $i$ den norske universitets- og høgskolesektoren [Time use, working hours, and time conflicts in the Norwegian university and college sector] [AFI Rapport 1, Issue]. https:// www.forskerforbundet.no/Documents/diverse/AFI_tidsbruksundersokelse2012.pdf?epslanguage $=$ no

Eldor, L., \& Shoshani, A. (2016). Caring relationships in school staff: Exploring the link between compassion and teacher work engagement. Teaching and Teacher Education, 59, 126-136. https://doi.org/10.1016/j.tate.2016.06.001

European Federation of Psychologists' Association. (2013). EFPA Review model for the description and evaluation of psychological tests: Test review form and notes for reviewers, $v$ 4.2.6. https://psyktestbarn.r-bup.no/cms/files/913

Fairlie, P. (2017). Work engagement and employee well-being. In R. J. Burke \& K. M. Page (Eds.), Research handbook on work and well-being (pp. 292-313). Edward Elgar.

Gillespie, N. A., Walsh, M., Winefield, A. H., Dua, J., \& Stough, C. (2001). Occupational stress in universities: Staff perceptions of the causes, consequences and moderators of stress. Work \& Stress, 15(1), 53-72. https://doi.org/10.1080/02678370117944

Gomes, A. R., Faria, S., \& Goncalves, A. M. (2013). Cognitive appraisal as a mediator in the relationship between stress and burnout. Work and Stress, 27(4), 351-367. https://doi.org/10.1 080/02678373.2013.840341

Han, J., Yin, H., Wang, J., \& Zhang, J. (2020). Job demands and resources as antecedents of university teachers' exhaustion, engagement and job satisfaction. Educational Psychology, 40(3), 318-335. https://doi.org/10.1080/01443410.2019.167 4249

Jordan, P. J., \& Troth, A. C. (2020). Common method bias in applied settings: The dilemma of researching in organizations. Australian Journal of Management, 45(1), 3-14. https://doi. org/10.1177/0312896219871976

Kaiser, S., Patras, J., Adolfsen, F., Richardsen, A. M., \& Martinussen, M. (2020). Using the job demands-resources model to evaluate work-related outcomes among Norwegian health care workers. SAGE Open, 10(3). https://doi.org/10.1177 $/ 2158244020947436$

Kesmodel, U. S. (2018). Cross-sectional studies-What are they good for? Acta Obstetricia et Gynecologica Scandinavica, 97(4), 388-393. https://doi.org/10.1111/aogs.13331
Kuvaas, B., \& Dysvik, A. (2010). Exploring alternative relationships between perceived investment in employee development, perceived supervisor support and employee outcomes. Human Resource Management Journal, 20(2), 138-156. https://doi. org/10.1111/j.1748-8583.2009.00120.x

Lauring, J., \& Selmer, J. (2015). Job engagement and work outcomes in a cognitively demanding context: The case of expatriate academics. Personnel Review, 44(4), 629-647. https://doi org/10.1108/pr-11-2013-0216

Lesener, T., Gusy, B., \& Wolter, C. (2019). The job demandsresources model: A meta-analytic review of longitudinal studies. Work \& Stress, 33(1), 76-103. https://doi.org/10.1080/026 78373.2018.1529065

Linley, P. A., Joseph, S., Harrington, S., \& Wood, A. M. (2006). Positive psychology: Past, present, and (possible) future. The Journal of Positive Psychology, 1(1), 3-16. https://doi. org/10.1080/17439760500372796

Marescaux, E., De Winne, S., \& Forrier, A. (2019). Developmental HRM, employee well-being and performance: The moderating role of developing leadership. European Management Review, 16(2), 317-331. https://doi.org/10.1111/emre.12168

Martinussen, M., Kaiser, S., Adolfsen, F., Patras, J., \& Richardsen, A. M. (2017). Reorganisation of healthcare services for children and families: Improving collaboration, service quality, and worker well-being. Journal of Interprofessional Care, 31(4), 487-496. https://doi.org/10.1080/13561820.2017.1316249

Martinussen, M., \& Richardsen, A. M. (2006). Air traffic controller burnout: Survey responses regarding job demands, job resources, and health. Aviation, Space, and Environmental Medicine, 77(4), 422-428.

Martinussen, M., Richardsen, A. M., \& Burke, R. J. (2007). Job demands, job resources, and burnout among police officers. Journal of Criminal Justice, 35(3), 239-249. https://doi. org/10.1016/j.jcrimjus.2007.03.001

Maslach, C. (1998). A multidimensional theory of burnout. In C. Cooper (Ed.), Theories of organizational stress (pp. 68-85). Oxford University Press.

Maslach, C., Jackson, S. E., \& Leiter, M. P. (1996). Maslach Burnout Inventory manual (3rd ed.). Consulting Psychologists Press.

Maslach, C., \& Leiter, M. P. (1997). The truth about burnout: How organizations cause personal stress and what to do about it. Jossey-Bass.

McClenahan, C. A., Giles, M. L., \& Mallett, J. (2007). The importance of context specificity in work stress research: A test of the Demand-Control-Support model in academics. Work and Stress, 21(1), 85-95. https://doi.org/10.1080/02678370701264552

McKeen, C. A., \& Burke, R. J. (1991). Work experiences and career success of professional women: Study design and preliminary findings. Canadian Journal of Administrative Sciences, 8 , 251-258.

Montero-Marin, J., Garcia-Campayo, J., Fajo-Pascual, M., Carrasco, J. M., Gascon, S., Gili, M., \& Mayoral-Cleries, F. (2011). Sociodemographic and occupational risk factors associated with the development of different burnout types: The cross-sectional University of Zaragoza study. BMC Psychiatry, 11, Article 49. https://doi.org/10.1186/1471-244x-11-49

Mudrak, J., Zabrodska, K., Kveton, P., Jelinek, M., Blatny, M., Solcova, I., \& Machovcova, K. (2018). Occupational well-being among university faculty: A Job demands-resources model. 
Research in Higher Education, 59(3), 325-348. https://doi. org/10.1007/s11162-017-9467-x

Naidoo-Chetty, M., \& Plessis, M. D. (2021). Systematic review of the job demands and resources of academic staff within higher education institutions. International Journal of Higher Education, 10(3), 268. https://doi.org/10.5430/ijhe.v10n3p268

Nerstad, C. G. L., Richardsen, A. M., \& Martinussen, M. (2010). Factorial validity of the Utrecht Work Engagement Scale (UWES) across occupational groups in Norway. Scandinavian Journal of Psychology, 51(4), 326-333. https://doi.org/10.1111 /j.1467-9450.2009.00770.x

Nurendra, A. M. (2018). The effect of job resources as moderating variable between job demands and work engagement on university lecturers. Malaysia Online Journal of Psychology \& Counseling, 5(1), 35-42.

Østlyngen, A., Storjord, T., Stellander, B., \& Martinussen, M. (2003). En undersøkelse av total arbeidsbelastning og tilfredshet for psykologer i Norge [A survey of total workload and satisfaction for psychologists in Norway]. Tidsskrift for Norsk Psykologforening, 40, 570-581.

Pretorius, T. B. (1994). Using the Maslach Burnout Inventory to assess educators burnout at a university in South-Africa. Psychological Reports, 75(2), 771-777.

Richardsen, A. M. (2019). Work engagement: Increasing employee well-being and organizational effectiveness. In R. J. Burke \& A. M. Richardsen (Eds.), Creating psychologically healthy workplaces (pp. 311-331). Edward Elgar. https://doi.org/10 $.4337 / 9781788113427.00025$

Richardsen, A. M., Burke, R. J., \& Leiter, M. P. (1992). Occupational demands, psychological burnout and anxiety among hospital personnel in Norway. Anxiety, Stress \& Coping, 5, 55-68.

Richardsen, A. M., Burke, R. J., \& Martinussen, M. (2006). Work and health outcomes among police officers: The mediating role of police cynicism and engagement. International Journal of Stress Management, 13(4), 555-574. https://doi.org/10.1037/10725245.13.4.555

Richardsen, A. M., \& Martinussen, M. (2005). The Maslach Burnout Inventory: Factorial validity and consistency across occupational groups in Norway. Journal of Occupational and Organizational Psychology, 77, 377-384. https://doi.org /10.1348/0963179041752691

Schaufeli, W. B. (2015). Engaging leadership in the job demandsresources model. The Career Development International, 20(5), 446-463. https://doi.org/10.1108/CDI-02-2015-0025

Schaufeli, W. B., \& Bakker, A. B. (2004). Job demands, job resources, and their relationship with burnout and engagement: A multi-sample study. Journal of Organizational Behavior, 25(3), 293-315. https://doi.org/10.1002/job.248

Schaufeli, W. B., Bakker, A. B., \& Salanova, M. (2006). The measurement of work engagement with a short questionnaire: A crossnational study. Educational and Psychological Measurement, 66(4), 701-716. https://doi.org/10.1177/0013164405282471

Schaufeli, W. B., Salanova, M., González-Romá, V., \& Bakker, A. B. (2002). The measurement of engagement and burnout: A two-sample confirmatory factor analytic approach. Journal of Happiness Studies, 3, 71-92. https://doi.org/10.1023/A: 1015630930326

Watts, J., \& Robertson, N. (2011). Burnout in university teaching staff: A systematic literature review. Educational Research, 53(1), 33-50, Article Pii 933214169. https://doi.org/10.1080/ 00131881.2011 .552235

Winefield, A. H., Gillespie, N., Stough, C., Dua, J., Hapuarachchi, J., \& Boyd, C. M. (2003). Occupational stress in Australian university staff: Results from a national survey. International Journal of Stress Management, 10(1), 51-63. https://doi. org/10.1037/1072-5245.10.1.51 